\title{
MEDiACIÓN CULTURAL Y MEDIACIÓN LINGÜÍSTICA EN LA FRONTERA DE GRANADA
}

\author{
Mercedes Abad Merino* \\ Universidad de Murcia
}

\begin{abstract}
Resumen
Durante la Baja Edad Media, en el sur de la península ibérica se configuró un espacio cultural de frontera en el que los límites quedaban establecidos, más allá de los umbrales políticos, por las marcadas diferencias culturales y religiosas de las comunidades que vivían a cada uno de sus lados. Dos formas de ver el mundo a través de dos lenguas completamente diferentes y alejadas entre sí, pero forzadas irremediablemente a establecer contactos tanto en tiempos de treguas como en tiempos de guerras: el comercio, la redención de cautivos, o las mismas relaciones de frontera, descansan en la intercomunicación, aun cuando sabemos que ésta no era posible entre todos los hablantes -se trata de dos comunidades mayoritariamente monolingües- sino a través de unos pocos que tienen en sus manos, de manera casi imperceptible, todo el poder que da el dominio de una lengua cuando los otros no la dominan. Traductores e intérpretes desempeñarán un papel fundamental, aunque no suficientemente valorado, no solo por sus saberes lingüísticos sino, especialmente, por su actuación como mediadores interculturales, desde el siglo XIII y hasta finales del XVI.
\end{abstract}

\section{Palabras clave}

Moriscos; mudéjares; intérpretes y traductores; mediadores interculturales; reino de Granada.

\begin{abstract}
During the Late Middle Ages, in the Southern of the Iberian Peninsula, a cultural border area was configured, where cultural and religious differences, more than political aspects defined the limits between both sides. Two different ways to see the world, through two completely different languages, far apart, but forced to remain in contact in war and peace. Trade, captives redemption, or even border relations themselves were based on intercommunication. However, we know that this communication was not always possible among all the speakers, given that most of them belonged to monolingual communities, so the intercommunication took place through those few who mastered the language. And those that had a good command of a language that most people ignored, achieved, almost imperceptibly, all the power knowledge gives. Translators and interpreters played an important role, although not valued enough, from the 13th century to the 16th century, not only for their language skills, but also because of their outstanding action as intercultural mediators.
\end{abstract}

\section{Keywords}

Moriscos; mudéjar; interpreters and translators; intercultural mediators; Kingdom of Granada.

\footnotetext{
* Dpto. Lengua Española y Lingüística General. Universidad de Murcia. Correo electrónico: mabad@um.es.
} 


\begin{abstract}
Resumo
Durante a Baixa Idade Média, no sul da península ibérica configurou-se um espaço cultural de fronteira cujos limites ficavam estabelecidos - para além do limiar político-pelas acentuadas diferenças culturais e religiosas das comunidades que habitavam em cada um dos lados. Duas formas de ver o mundo através de duas línguas completamente diversas e afastadas entre si, mas irremediavelmente forçadas a estabelecer contatos, quer em tempos de tréguas, quer em tempos de guerras: o comércio, a redenção de cativos, ou as próprias relações de fronteira, assentavam na intercomunicação. Esta não era possível entre todos os falantes, porque eram duas comunidades maioritariamente monolingues, mas era concretizada através de uns poucos que detinham nas suas mãos, de maneira quase impercetível, todo o poder proveniente do domínio de uma língua quando os outros não a dominam. Tradutores e intérpretes jogaram um papel fundamental, embora não suficientemente valorizado, não só pelas suas competências linguísticas, como também pela sua atuação enquanto mediadores interculturais, desde o século XIII e até os finais do século XVI.
\end{abstract}

\title{
Palavras-chave
}

Mouriscos; mudéjares; tradutores e intérpretes; mediadores interculturais; Reino do Granada.

\section{Introducción}

La frontera del reino de Granada con el de Castilla establecía mucho más que una delimitación política o geográfica, puesto que era el límite entre dos universos distintos, el islámico y el cristiano, con diferentes concepciones de mundo y con lenguas muy distintas y alejadas. La diferencia lingüística -árabe o algarabía y castellano-, lejos de constituir un rasgo periférico, constituye uno de los rasgos caracterizadores más evidentes y a la vez más íntimos de esta sociedad, pues la lengua configura la visión del mundo de los dos grupos. Tanto en el periodo fronterizo, con la existencia del reino nazarí, como en el morisco, después de la Conversión General, las relaciones entre ambas comunidades se llevaban a cabo la mayor parte de las ocasiones a través de un intérprete. Cuando las diferencias lingüísticas eran las propias y esperables en dos reinos diferentes, principalmente fueron granadinos conocedores del castellano, como mercaderes, alfaquíes o intérpretes oficiales, los que asumían esas tareas, aunque también encontraremos en este papel a judíos y a algún cristiano; después, cuando Granada se incorporó a la corona de Castilla y con ello a la lengua del reino conquistador, serán mudéjares y, posteriormente, moriscos quienes de forma mayoritaria desempeñen esta función: los encontramos como intérpretes en procesos judiciales, como lenguas en el campo de batalla y en la vida cotidiana, como romanceadores de escrituras árabes e incluso como predicadores o traductores de catecismos, aunque también identificamos algunas veces a cristianos viejos, judeoconversos o incluso algunos miembros del clero en este papel.

Son, en cualquier caso, mucho más que meros agentes lingüísticos, puesto que actúan como puente necesario entre dos mundos diferentes. Su importancia, sin embargo, no siempre se ve reflejada en los documentos de la época, de los que se deslizan casi imperceptiblemente en muchas ocasiones. En otras, por el contrario, se convierten en protagonistas involuntarios del acto comunicativo, alterando así el papel neutral que se le debe suponer a un intérprete. 
Como hemos dicho, no siempre eran profesionales, pues estas funciones podían recaer en todo aquel con suficiente competencia lingüística en las dos lenguas -aunque ser bilingüe no garantice ser un buen intérprete- desde un soldado a un alfaquí, un romanceador o un vecino, algo que, por otra parte, no se diferencia demasiado de lo que sucede en la actualidad, pues cuando es necesario mantener la comunicación entre hablantes con distintas lenguas y culturas y no existe una institución pública que ofrezca esa figura mediadora, se acude a conocidos, parientes, o incluso hijos menores, que proporcionen esa ayuda ${ }^{1}$. El conocimiento de la lengua es el eje en torno al cual gira toda la cuestión de la mediación en sus distintos planos.

Un buen ejemplo de esto lo encontramos en el pleito entre el marqués de los Vélez y Baza por los límites entre Oria y Cúllar en $1535^{2}$, en pleno proceso de delimitación de jurisdicciones territoriales tras la conquista, que constituye un tipo documental bastante generalizado en los municipios fronterizos, en los propios de Granada y en todos los niveles judiciales castellanos, desde el concejil hasta el Consejo Real, con el paso intermedio de la Chancillería granadina. En el testimonio de Catalina Gómez, de cuarenta y cinco años de edad, descubrimos quién podía desempeñar esa labor mediadora entre los vecinos:

"hablava en la calle junto a casa desta testigo, y no entendió con quién hablava ni lo que hablava porque hablava en algarabia. Y a la sazon entró en la dicha casa desta testigo una hija suya que se llama Valentina, y esta testigo le preguntó que qué era lo que el dicho Francisco Hernandez hablava en algarabia. La qual dixo a este testigo quel dicho Francisco Hernandez rogava e importunava a un cristiano nuevo que iba con él que jurase e dixese su dicho en cierto pleito. E que el dicho cristiano nuevo le respondia que él no sabia nada de aquello que le decia el dicho Francisco Hernández, e qué queria que jurase".

Después preguntaron también a la niña Valentina, de doce años, y en su testimonio puede leerse:

"y le decia en lengua araviga, la qual entiende este testigo bien, que fuese con él a decir su dicho en cierto pleito (...) y el dicho cristiano nuevo vio este testigo que respondio: "Yo no sé nada de eso que quereis que diga»".

\footnotetext{
1 Raquel SANTANa FalCón, "El mediador cultural en los servicios públicos: una nueva profesión", Estudios de Traducción, 3 (2013), p. 35.

2 Archivo Municipal de Baza (Granada). Leg. 90. Cit. en Mercedes Abad Merino, "Intérpretes latentes y patentes en el periodo morisco (1501-1568). Del medio oral al medio escrito", Miscelánea Medieval Murciana, XXIX-XXX (2006), p. 22.
} 
En este trabajo partimos de la idea de que en la frontera granadina el traductor desempeñaba en muchas ocasiones el papel de mediador, como mostraremos, con lo que podremos contribuir en cierta medida al debate actual en torno a la consideración del intérprete como intermediario lingüístico.

Las labores del traductor no pueden abstraerse del momento histórico en el que se desarrollan. Están estrechamente relacionadas con la historia, por lo que los valores de cada época llegarán a influir en la tarea de estos personajes. Esta labor, tanto si se desarrolla en un ámbito erudito como si se trata de traducciones cotidianas, mostrará con toda certeza una inestimable transferencia de valores que nos acercarán mucho más a la época y a la situación.

En esta ocasión vamos a detenernos precisamente en el papel que intérpretes y traductores pudieron desempeñar como puente entre dos orillas cercanas y alejadas al mismo tiempo. Intentaremos comprobar mediante distintos tipos de testimonios, esa potencial capacidad para la mediación, aunque teniendo siempre presente que sería un anacronismo establecer más paralelismos entre estas figuras, pues aunque algunas propuestas actuales podrían aplicarse a la situación y época que nos ocupa, en la que la diferencia de culturas es la que establece las principales barreras internas y externas y la que requiere de un intermediario eficaz, difícilmente podríamos entender la mediación como una estrategia para la convivencia y el entendimiento entre culturas, pues el fin último suele ser más prosaico.

Documentar históricamente estas ideas que esgrimimos no es tarea fácil, ya que, como hemos mostrado en otras ocasiones ${ }^{3}$ no contamos con un corpus específico ni abundante al que poder acudir para obtener ejemplos. En esta ocasión nos serviremos principalmente del pleito entre doña María de Luna, viuda de Enrique Enríquez, con el marqués de los Vélez, don Pedro Fajardo Chacón, por los límites de las villas de Orce y Vélez Blanco pues este tipo documental, por sus particularidades intrínsecas, como la de necesitar de testigos moriscos ancianos ${ }^{5}$, nos ofrece unas posibilidades superiores a las de cualquier

\footnotetext{
Mercedes Abad Merino, "La ejecución de la política lingüística de la Corona de Castilla durante el siglo XVI o «No hablar algaravia so pena de çient açotes»", Estudios de sociolingüística: sincronía y diacronía, Pilar Díez de Revenga y José Ma Jiménez (coords.), Diego Marín Editor, Murcia, 1999, pp. 9-34; "Exeas y alfaqueques. Aproximación a la figura del intérprete de árabe en el periodo fronterizo (siglos XIII-XV)", Homenaje al profesor Estanislao Ramón Trives, Agustín Vera Luján y otros (eds.), Servicio de Publicaciones de la Universidad de Murcia, Murcia, 2003, pp. 35-50; "Aquí hay necesidad de persona capaz en muchas lenguas. El oficio de intérprete en las últimas fronteras de Castilla", Tonos digital. Revista electrónica de estudios filológicos, 10 (2005). <www.tonosdigital.es/ojs/index.php/tonos/article/view/425>; "Intérpretes latentes y patentes...", pp. 9-26; "El intérprete morisco. Aproximación a la historia de la traducción cotidiana en España en el ocaso de la Edad Media", Hermeneus, 10 (2008), pp. 23-53; "La traducción de cartas árabes en un pleito granadino del siglo XVI. El fenómeno del romanceado como acto judicial: Juan Rodríguez y Alonso del Castillo ante un mismo documento", Al-Qántara, 32-2 (2011), pp. 481-518.

4 Archivo General de Simancas. Consejo Real. Leg. 54.

5 Mercedes Abad Merino y Juan Francisco Jiménez Alcázar, "Item si sabe... El testigo morisco en los pleitos civiles castellanos", Carlos V. Los moriscos y el Islam, Ma Jesús Rubiera (coord.), Sociedad Estatal para la Conmemoración de los centenarios de Felipe II y Carlos V-Universidad de Alicante, Madrid, 2001, pp. 27-38.
} 
otra tradición discursiva, pues hace necesaria la presencia de intérpretes que actúen como intermediaros entre las partes. Si, como en este caso, además podemos conocer sus nombres y hay constancia explícita de su labor -lo que no siempre sucede- se dan las condiciones más favorables para el estudio de esta compleja situación comunicativa:

[23r]

“...para la Camara de su altesa, no dixese ni descubriese cosa alguna de lo que dicho avia a ninguna de las partes ni ante persona alguna, fasta tanto que fuese fecha publicaçion de su dicho. E porque dixo que no sabia escriuir no lo firmo, e firmaronlo los dichos ynterpetres e yo, el dicho escriuano." [Firmas:

Cardenas, ynterpete (sic)

Bartolome de Ayala

Diego Gonzalez de Santyllana]

\section{Mediación en la frontera}

\subsection{En torno al concepto de mediación y mediador en perspectiva diacrónica}

No vamos a entrar en el complejo debate que desde hace décadas se ha mantenido en torno a qué ha de entenderse por mediación cultural o intercultural, ya que no es el propósito de este trabajo y excedería en mucho los límites fijados. Hemos de elaborar nuestra propuesta a partir de la información encontrada en los documentos, no siempre abundante y raras veces explícita, lo que nos mantendrá con los pies en el suelo y alejados de la tentación de teorizar en exceso, por lo que adoptaremos aquellos postulados que pueden ser aplicados desde una perspectiva diacrónica a una situación como la que ahora analizamos; lo que significa no buscar en la intermediación de estos siglos el fin integrador que en nuestros días se persigue, pues sería un anacronismo.

Así, por ejemplo, compartimos esencialmente la concepción de García Castaño y Barragán ${ }^{6}$ quienes consideran la mediación intercultural como un recurso al alcance de personas de culturas diversas, que actúa como puente, con el fin de facilitar las relaciones, fomentar la comunicación y promover la integración entre personas o grupos, pertenecientes a una o varias culturas.

Aunque incitar hacia la integración no será el primer objetivo de nuestros agentes lingüísticos, pues si bien es cierto que desde esta perspectiva la mediación intercultural se entiende como una herramienta cotidiana para comprender la diversidad cultural y para relacionarse con ella -desde el acuerdo y el consenso preferentemente-, como una práctica cotidiana en las relaciones humanas, tampoco lo es menos que en la época que

6 Francisco Javier García Castaño y Cristina Barragán Ruiz-Matas, "Mediación intercultural en sociedades multiculturales: hacia una nueva conceptualización", Portularia, 4 (2004), pp. 130-131. 
estamos abordando, a lo más que se podía aspirar era al entendimiento lingüístico, puesto que la disposición y voluntad de las partes implicadas en el proceso para establecer puentes o lazos sociales era prácticamente nula, e incluso políticamente imposible, ya que la equiparación entre lengua, cultura y religión era la base de la concepción de la diversidad y la única forma de identificar y caracterizar al grupo del otro. No podemos asumir "el mito de las culturas" porque no se basa en una perspectiva real y distorsionaría el planteamiento y las conclusiones del enfoque que ahora planteamos. Este mito se basa, como señala Salicrú ${ }^{7}$ en una perspectiva tan idílica como irreal que no recoge en absoluto el tipo de relación existente entre judíos, moros y cristianos, pues esa convivencia armónica es más supuesta que real ${ }^{8}$. Por supuesto, encontraremos casos de tolerancia ${ }^{9}$, de cooperación e incluso de amistad, pero sería más apropiado hablar de "sociedades paralelas"10. Por todo ello, quizás sería preferible referirnos a esta figura con la denominación de intermediario lingüístico ${ }^{11}$.

Los testimonios que han llegado hasta nosotros destacan normalmente los aspectos más negativos de la convivencia, ya que lo que fluye sin problemas y pacíficamente no suele ser recogido, ni antes ni ahora, porque no llama la atención ni provoca reacciones encontradas, lo que no significa que no fuera frecuente y cotidiano, o que no existieran las relaciones continuadas y estables, como las comerciales ${ }^{12}$, por ejemplo.

Partimos, pues, como se ha dicho antes, de la idea de mediador, aplicado a la figura del intérprete, como persona que sirve de puente entre lenguas y culturas, tal y como lo define Boechner ${ }^{13}$, aunque esto suponga una intervención más visible y personal de la que cabría esperar de un intérprete. Hay gran debate en torno a este aspecto, pues

\footnotetext{
Roser SAlicrú I Lluch, "Crossing Boundaries in Late Medieval Mediterranean Iberia: Historical Glimpses of Christian-Islamic Intercultural Dialogue", International Journal of Euro-Mediterranean Studies, 1-1 (2008), p. 35.

8 Serafín Fanjul, "El mito de las tres culturas", Revista de Occidente, 224 (2000), pp. 9-30.

9 En la franja murciano-granadina, contamos con los casos analizados por José GARCía ANTóN, "La tolerancia religiosa en la frontera de Murcia y Granada en los últimos tiempos del reino nazarí", Murgetana, 57 (1980), pp. 133-143. Sobre el conjunto del planteamiento, véase el estudio de Manuel GonZÁLeZ JimÉNEZ, "El problema de la tolerancia en la España de las Tres Culturas", Pluralismo, tolerancia y multiculturalismo. Reflexiones para un mundo plural, P. Badillo O'Farrel (coord.), Madrid, 2003, pp. 125-141; reeditado en un volumen recopilatorio de diversos trabajos del historiador sevillano: A través de Sevilla y Andalucía. Estampas de Historia Medieval, Universidad de Sevilla, Sevilla, 2011, pp. 287-302.

10 Robert I. Burns, Jews in the notarial culture: Latinitate wills in Mediterranean Spain, 1250-1350, University of California Press, Berkeley, 1996, pp. 17-22.

11 Zahra El Hasnaour Ahmed, "Retos y técnicas en la mediación cultural", Traducción como mediación entre lenguas y culturas, Carmen Valero (ed.), Universidad de Alcalá de Henares, Alcalá de Henares, 2005, pp. 83-87.

12 Roser Salicrú I Lluch, "Crossing Boundaries in Late Medieval Mediterranean Iberia...".

13 St. Boechner (ed.), The Mediating Person: Bridges between Cultures, Schenkman, Cambridge, 1981, apud: Raquel SANTANA FALCón, "El mediador cultural...", p. 38.
} 
algunos autores como Kondo ${ }^{14}$ o Roy ${ }^{15}$ consideran que si el mediador para ser capaz de traducir un significado debe manejar ideas y no solo palabras, ese hecho ya no podría considerarse traducción, mientras que otros como Brislin ${ }^{16}$ o Knapp-Potthof y Knap ${ }^{17}$ sí admiten la intervención del intérprete y su visibilidad como un ingrediente más de la mediación, en la que pude elaborar sus propias iniciativas ${ }^{18}$. Nosotros debemos aceptar como válidas las dos posturas, puesto que unas veces es suficiente con encontrar el significado equivalente, pero en otras ocasiones es inevitable que el traductor recurra a ideas y conceptos para establecer la equivalencia y se convierta en protagonista inesperado.

En nuestros días, cuando se aborda el problema de comunicación en las sociedades multiculturales, se distinguen diversos modelos de intermediación lingüística, según sea el protagonismo que adquiere en el proceso el traductor. Así, en el ámbito sanitario, Cambridge ${ }^{19}$ diferencia el modelo abogacía y el modelo imparcial. En el primer caso el intérprete incluye entre sus funciones la de abogar, en el sentido pleno del término, por aquel que necesita sus servicio de tal manera que llega a tomar partido, a aconsejarlo o incluso a hacer preguntas propias o a dar su opinión; en el otro caso -el imparcial-, el intérprete repite exclusivamente lo que oye y se convierte en el alter ego de la persona cuyo discurso está interpretando de tal manera que la comunicación pueda llevarse a cabo como si el intérprete no estuviera presente. Hemos elegido estos dos modelos porque reflejan muy bien las situaciones que pueden mostrarse en los documentos de esta época.

Por una parte, nos encontramos al intérprete imparcial, o más bien habría que decir que no lo encontramos, pues solo tenemos noticia de su presencia porque el escribano lo hace constar al principio de cada testimonio, sirviéndose de distintas fórmulas:

El dicho Gil Arramit, vesino de la dicha villa de Cullar, testigo sobredicho, jurado e preguntado por el dicho jues e por boca e palabra de los dichos ynterpetres dixo e declaro en su dicho lo syguiente [fol. 13r.].

\footnotetext{
14 M. KonDO, "What conference interpreters shoulds not be expected to do", The Interpreter's newsletter, 3 (1990), pp. 59-65.

15 C. Roy, "A sociolinguistic analysis of the interpreter's rol in simultaneous talk in face-to-face interpreted dialogue", Sign Language Studies, 74 (1992), pp. 21-61.

16 Richard Brisun, Cross-cultural encounters: face to face interaction. Pergamon, Oxford, 1987.

17 A. Knapp-Potthoff y K. KnAPP, "The man (or woman) in the middle: discoursal aspects of non-professional interpreting", The Mediating Person..., pp. 181-201.

18 Raquel Santana Falcón, "El mediador cultural...”, p. 38.

19 J. CAmBridge, "Interlocutor roles and the pressures on interpreters", Nuevas necesidades para nuevas realidades, C. Valero y G. Mancho (eds.), Universidad de Alcalá de Henares, Madrid, 2002, pp. 119-123, en Raquel Santana FaLCÓn, "El mediador cultural...", p. 38.
} 
El dicho Alonso Lavbiui, chistianos nuevo, vesino del lugar de Lucar, testigo sobredicho, jurado e preguntado por el dicho jues e por boca de los dichos ynterpetres lo que dixo e depuso es lo syguiente [fol. 23r].

El dicho Alonso de Barrios, christiano nuevo, vesino de la villa de Seron, testigo sobredicho, jurado e preguntado por el dicho jues e segund declaraçion de los dichos ynterpetres, dixo lo syguiente [fol. 44r $]^{20}$.

En este caso las palabras del testigo llegan al receptor sin ningún tipo de interferencia:

A la dozena pregunta dixo que la sabe commo en ella se contiene [tachado: por vista e por oyda]. Fue preguntado commo la sabe. Dixo que porque vio que dos vezes los christianos de Lorca fisyeron danno a los vesynos de Cullar. Y que los de Velez entregaron el rastro a los de Orze en el Agua Blanca, e los de Orze entregaron el rastro a los de Cullar. Y que el robo se fiso a su padre deste testigo, e quel hera a la sazon de hasta ocho annos. Fue repreguntado que commo se acordava de lo que dicho avia seyendo de tan poca hedad. Dixo que quando a vno le davan vn palo en el ojo syenpre se acordava dello. Es que por esto se acordava este testigo que por el robo que avian fecho a su padre se acordava el avnque fera ninno. E que por esto la sabe [fol. 6v].

Incluso podemos leerlas como discurso directo reproducido, tal cual fueron pronunciadas por el testigo:

Fue preguntado sy fue sobornado, corruto o atemorisado [tachado: por al] o dadivado por alguna de las partes para que dixese el contrario de la verdad e lo que no sabia. Dixo que no fue sobornado por ninguna de las partes, pero que Alamar, alguasil de Orze, fue por él, e le dixo: «Tu as de yr a ser testigo pues fuyste vesino de Orze e yo te dare tanto commo a vn segador» [fol. 25r].

Pero en otras ocasiones el intérprete se manifiesta, abandonado así la discreción que ha de caracterizarlo, porque considera necesario intervenir de una manera más contundente que garantice la calidad de su mediación. Estas incursiones pueden afectar a distintos planos comunicativos, pues unas veces se refieren directamente al emisor y en otras ocasiones se producen ante las dudas que despierta el contenido del mensaje.

\footnotetext{
20 Archivo General de Simancas. Consejo Real. Leg. 54. Las siguientes referencias de fragmentos documentales, pertenecen a este pleito entre doña María de Luna y el marqués de los Vélez. Los marcados son nuestros en todos los casos, así como el foliado, ya que la pieza está sin numerar.
} 
Un buen ejemplo de ello lo encontramos en la adaptación de las medidas itinerarias:

A las diez e syete preguntas dixo que puede aver desde Orze a Velez veynte e quatro millas e declararon los ynterpetres que heran seys leguas a quatro millas la legua [fol. 8v].

A la diez e syete preguntas dixo que le han dicho que desde Orze a Velez el Blanco ay veynte e quatro millas que segund declaraçion de los ynterpetres son seys leguas [fol. 13r].

A la diez e syete preguntas dixo que no sabe que tanto ay desde Orze a Velez porque no lo midio pero que puede aver veynte millas que segund dixeron los ynterpetres son çinco leguas $[14 \mathrm{v}]$.

En el testimonio de Pedro de Aguilar, alguacil de Lúcar, de sesenta años, se pone de manifiesto este aspecto que exponemos, al cobrar protagonismo ambos intérpretes:

A la quinta pregunta dixo que sabe que los vesinos de Orze, en tienpo de moros, tenien e poseyan estos dichos terminos desde los dichos mojones por suyos e como suyos. E segund declaraçion del ynterpetre de la villa de Veles que se dise Fernando de Cardenas, dixo que este testigo vario en esta pregunta, porque tres vezes le pregunto sy hera la villa de Orze sennora destos terminos por los dichos mojones, asy en tienpo de moros commo de christianos, e avia dicho que sy. E segund declaraçion de Bartolome de Ayala, ynterpetre de la parte de Orze, dixo que quando pregunto el dicho Fernando de Cardenas a este testigo sy se vsaua lo susodicho en tienpo de moros e christianos, avia respondido este testigo que no se acordaua de lo del tienpo de christianos, porque hera forastero. E luego, el dicho jues dixo que se le pareçia que segund las vezes que le pregunto esta pregunta el ynterpetre de Veles, que se contradixo este testigo en la respuesta que dio a la pregunta [fol. $21 \mathrm{v}]$.

En estas circunstancias podemos hablar verdaderamente de agentes lingüísticos, pues no solo traducen las palabras de los testigos, sino que valoran la credibilidad de sus testimonios, como sucede con el testigo Gómez Fajardo, vecino de Serón, de sesenta años:

Fue preguntado que cómmo ha dicho que sabia la dicha pregunta que en tienpo de moros e de christianos los de Orze heran sennores de los dichos terminos commo en la pregunta se qontiene, e dentro de los dichos mojones. Dixo que no sabe mas de commo agora los vee rennir por el dicho termino. $\mathrm{E}$ asy dicho esto, el dicho Fernando de Cardenas, ynterpetre, dixo que le pareçia que variava. E asymismo, el dicho Bartolome de Ayala, preguntado por el dicho jues, so cargo del juramento que fecho avia, que que le pareçia 
de lo que este testigo desia. Dixo que le pareçia que se contradesia, y el dicho jues dixo que se ase[borrado] asy e que asy le pareçia a el segund la relaçion de los yn[terpe]tres, e que el castigo desto reseruaua para despues de la publicaçion [fol. 34v].

\subsection{Intermediarios lingüísticos en tiempos de conflicto}

Del pacto de Jaén en 1246 hasta la capitulación de Boabdil, en lo que conocemos como época fronteriza, los enfrentamientos militares entre los reinos de Castilla y Granada salpicaron el periodo, y a momentos de guerra les sucedían periodos de tregua intermitentes y frágiles ${ }^{21}$, aunque más interesante aún fueron las complejas relaciones de cercanía entre los núcleos situados en vanguardia:

A la otana pregunta dixo que oyo desir que en tienpo que tenian treguas los vesinos de Veles con Lorca e Caravaca, que quando algunos fasian algun danno o salteavan, que trayan los christianos el rastro hasta el termino de Veles, e los de Veles sy no salian con el rastro de su termino, pagauan o se boluian a guerra [fol. $37 \mathrm{v}]$.

Los contactos entre cristianos y musulmanes eran frecuentes por razones de vecindad o de comercio ${ }^{22}$, lo que daba lugar a roces y desencuentros que era preciso solucionar. Era un mundo de contrastes en el que ambas comunidades se vieron forzadas a institucionalizar la forma de sus relaciones. Así se refleja en los recuerdos de los testigos, cuando mencionan lo que era costumbre en tiempo de moros:

A la terçera pregunta dixo que sabe que por cabsa de los rastros que se davan en tienpo de moros a otros se conosçian los terminos propios de cada lugar. Preguntado commo lo sabe, dixo que porque vn Abduladin, vesino de Veles, se desposo con vna fija del cabdillo de Baça, e trayendole su esposa treynta de cavallo e con ellos este testigo. Salio el dicho Abduladin al camino e que les dixo: "Sennores, no paseys de aquí, porque yo estoy en paz con los christianos e somos flacos. Tornaos desde aquí, que este es el termino de

21 Diego I. Melo Carrasco, "En torno al vasallaje y las parias en las treguas entre Granada y Castilla (siglos XIII-XV): una posibilidad de análisis", Medievalismo, 22 (2012), pp. 139-152. También cabe referir la monografía del arabista chileno: Las alianzas y negociaciones del sultán. Un recorrido por la historia de las "relaciones internacionales" del Sultanato Nazari de Granada (siglos XIII-XV), EDITUM, Murcia, 2016, así como la recopilación documental sobre el tema: Compendio de cartas, tratados y noticias de paces y treguas entre Granada, Castilla y Aragón (siglo XIII-XV), EdITum, Murcia, 2016.

22 Juan Francisco JiméneZ AlCÁZAR, "Comerciar en la frontera de Granada: espacios económicos asimétricos y periféricos (siglos XIII-XVI)", El mercat: un món de contactes i intercanvis, Flocel Sabaté (ed.), colec. Aurembiaix, Pagès Editors, Lleida, 2014, pp. 167-188. 
Veles». Fue preguntado que en que parte se le entrego al dicho Abduladin la dicha su esposa. Dixo que en la fuente del Alfaguara, e que por esto lo sabe, e que no vio entregar otros rastros [fol. 34r].

Caso muy similar al que se puede documentar en las palabras de Francisco Abohanbre, morisco, testigo de Serón:

A la terçera pregunta dixo que sabe que los dichos rastros se entregauan vnos lugares a otros en el cabo de sus terminos. Fue preguntado commo lo sabe. Dixo que no sabe cómmo se entregan los rastros ni dónde mas de quanto le dixo vna vez vn adalid veniendo que venian de Caravaca con vna cavalgada que trayan de dos christianos, que este testigo venia cansado e llegando al puerto del Saladillo le dixo: "Ya estamos seguros del rastro, que estamos en lo de Orze, y no entremos en el termino de Veles, porques Aduladin (sic) $\mathrm{ma}[$ borrado] que estan en la paz». E que por esto lo sabe [fol. 36v].

La captura de cautivos así como su liberación, en uno y otro lado de la frontera, era una actividad habitual en tiempo de guerra que requería de los servicios de ejeas y alfaqueques, figuras que ejercían de verdaderos intermediarios entre ambos reinos, con nombramiento real en algunos casos o concejil en otros, quienes entre otras muchas funciones desempeñaban la de intérprete por necesidad. El rey Alfonso X en las Partidas regula su nombramiento (Partida II, título XXX, ley 1) y describe los requisitos que han de cumplir, que se asemejan bastante a los que en la actualidad se le piden a un mediador ${ }^{23}$ :

"E si sabidores fueren de la lengua, entenderán lo que dixeren amas las partes, e sabran responder a ello, e decir otrosi a cada vno lo que conviene"

Eran figuras cotidianas y comunes, como se puede deducir de los testimonios de algunos testigos, que lo incorporan como un elemento más de la situación descrita, sin necesidad de más explicaciones, tanto en el caso del alfaqueque como en el del ejea:

Preguntado cómmo lo sabe, dixo que este testigo teniendo ganado en el termino de Huescar, lo qual guardaua vn negro esclavo deste testigo e otros dos onbres, le dixeron que le avian llevado el dicho negro. E que este testigo tomo vn vallestero e otros dos onbres, e fueron hasta donde tomaron el dicho negro, y syguieron el rastro, y llevaronlo hasta el puerto Saladillo. E de alli fueron a Velez, y entró al cabdillo que se desya Abduladin, e le dixo:

23 Mercedes ABAD Merino, "Exeas y alfaqueques...”. 
«Sabete que me han llevado el negro y avemos traydo el rastro fasta el puerto Saladillo». E quel dicho Abduladin dixo al alhaqueque que sy hera el puerto del Saladillo de los de Velez, e que respondio el alhaqueque que sy. E que otros tres onbres de Velez dixeron que el puerto del Saladillo partya termino entre Velez e Huesca e Orze. E que ellos se boluieron, e dende a quinse dias, los de Veles tomaron el rastro y enbiaron el negro. E que por esto sabe lo que dicho ha [fol. 19v].

A la terçera pregunta de las sennales de los rastros, dixo que este testigo vio en la villa de Albox e syendo el alcaide della, que vino a él vn vallestero de monte, e le dixo cómmo se entregauan los rastros en fin de los terminos. E que despues vino a el vn exea cristiano viejo e con el vn vallestero, christiano viejo, e le dixeron que avian traydo vn rastro hasta termino de Albox. Por eso que le tomase que alli se lo entregaron en el cabo de su termino [fol. 32r].

Con toda probabilidad, en este contexto podremos encontramos con las mismas condiciones que envuelven en la actualidad la mediación lingüística en tiempos de conflicto, tema que está recibiendo especial atención en los últimos años ${ }^{24}$ desde una perspectiva multidisciplinar. Después, una vez conquistada Granada, podemos seguir manteniendo este enfoque, ya que entre revueltas y rebeliones, el clima de conflicto no desapareció y las presiones a que estuvieron sometidos intérpretes e interpretados fueron muchas y de la más diversa índole.

Podemos aplicar a este momento las mismas condiciones que señalan Payás y Garbarini25, cuando estudian la figura del intérprete en el periodo colonial, quien teóricamente debe ocupar un lugar neutral entre las partes en conflicto. Pero lo cierto es que en muchas ocasiones, debido a las presiones y a las circunstancias a las que estaba sometido, terminaba por vincularse a una de las partes, casi siempre a aquella que lo había contratado, aunque esa vinculación también puede fundamentarse en afinidades de origen o en otras lealtades. Sea como fuere, esto propiciaba la confusión en la función del intérprete, que puede definirse como polifacética.

En entornos bélicos o de conflicto, los intérpretes no siempre pueden ser objetivos; es más, en muchas ocasiones son claramente parciales y corren el riesgo de llegar a ponerse al servicio del enemigo, o incluso a actuar por su cuenta.

El intérprete no solo debe conocer las dos lenguas, sino que debe saber usarlas, lo que implica que además de sus saberes lingüísticos debe tener suficiente habilidad

24 Mona BAKER, Translation and Conflict: A Narrative Account, Routledge, New York-London, 2006. Moira Inghilleri y Susan-Ann Harding, "Translation and Violent Conflict", The Translator. Studies in Intercultural Communication (Special Issue), 16-2 (2010), pp. 165-173. Gertrudis PAYÁs y José Manuel ZaVala (eds.), La mediación lingüístico-cultural en tiempos de guerra, Universidad Católica de Temuco, Temuco, 2012. 25 Gertrudis PaYÁs y Carmen Gloria GaRBARINI, "La relación intérprete-mandante: claves de una crónica colonial para la historia de la interpretación”, Onomazéin, 25 (2012), pp. 347-348. 
para combinar aquellos con los saberes socioculturales. En este sentido, las cuatro competencias que debe tener un intérprete señaladas por Zahra El Hasnaoui ${ }^{26}$, son plenamente extrapolables a la época que estudiamos y a la situación comunicativa específica: competencia lingüística; competencia sociocultural; competencia pragmática y competencia estratégica.

El mediador, pues, ejerce no solo una mediación lingüística, sino también cultural y los participantes en ese proceso manifiestan un elevado grado de dependencia ${ }^{27}$.

En el marco del Mediterráneo occidental, Salicrú i Lluch $^{28}$ ofrece algunos ejemplos de las relaciones entre la Corona de Aragón y el reino de Valencia con el reino nazarí de Granada durante la Baja Edad Media, y muestra que los mediadores -mercaderes unas veces; oficiales reales, otras- no solo cumplían con el papel de intérprete, sino que necesitaban ser expertos conocedores de los códigos culturales de los dos mundos, del propio y el del otro. Habla de tres tipos de agentes diplomáticos o mediadores enviados a Granada y al norte de África, que pueden encontrar su equivalente en cierta medida en el siglo XVI: el de los oficiales reales con cargos relacionados con la frontera; el de los mercaderes con intereses en los países islámicos o residentes en ellos y el de los mudéjares.

Este último caso pone de manifiesto que el mediador no lo es solamente por el dominio de la palabra, pues en la Corona de Aragón había cristianos muy hábiles en el manejo del árabe, sino que despertaban un sentimiento de solidaridad islámica ${ }^{29}$ que generaba un clima de confianza con su interlocutor, lo que puede justificar que siglos después, cuando los interlocutores presentan las mismas características socioculturales, se siga prefiriendo al morisco para establecer una comunicación más fluida con sus semejantes.

Efectivamente, si tenemos en cuenta los abundantes testimonios que nos hablan de los moriscos como gentes de poco crédito, se hace difícil imaginarlos como mediadores, pues a simple vista no parecían gozar de la confianza de los cristianos viejos, como ponen de manifiesto las palabras del cura de Macael, que cuando se refiere a ellos no muestra ninguna compasión: "no hay en esta tierra gente mas vil que las de dicho lugar [Lubrín], e es publica voz e forma que son los mayores cornudos desta tierra", y añade que "oyo decir a un christiano nuevo, vezino de la villa de Alborea, que por seis maravedies que este testigo le diese, juraría que avia visto parir a una mula" ${ }^{\prime 30}$. En este

\footnotetext{
26 Zahra el Hasnaoui Ahmed, "Retos y técnicas..."

27 Giuseppe Trovato, "La mediación cultural en el ámbito sanitario: algunas reflexiones relativas a las problemáticas culturales y al papel del mediador", Redit, 8-1 (2012), p. 31.

28 Roser SAlicrú I LluCh, "Más allá de la mediación de la palabra: negociación con los infieles y mediación cultural en la Baja Edad Media", Negociar en la Edad Media, M.T. Ferrer, J.M. Moeglin, S. Péquinot y M. Sánchez (eds.), CSIC, Barcelona, 2005, pp. 409-439.

29 Roser Salicrú i Lluch, "Mudéjares y cristianos en el comercio con Berbería: quejas sobre favoritismo fiscal y acusaciones de colaboracionismo mudéjar, una reacción cristiana a la defensiva", De mudéjares a moriscos: una conversión forzada. VIII Simposio Internacional de Mudejarismo, Teruel, 15-17 de septiembre de 1999, vol. 1, Instituto de Estudios Turolenses, Teruel, 2002, pp. 283-301.

30 Mercedes Abad Merino y Juan Francisco Jiménez AlCÁZar, “Item si sabe...”, p. 31.
} 
ambiente de desconfianza, como decíamos, solo ese sentimiento de solidaridad islámica y el efecto balsámico que se puede producir en situaciones comunicativas difíciles o comprometidas, pueden explicar la aceptación del morisco como agente lingüístico por ambas partes en conflicto.

Cuando la situación empeoró, en el contexto previo de la sublevación de 1568 y como consecuencia de ella, se les prohibió portar armas. En este sentido, es interesante destacar que cuando en 1573 se prohíbe a los mestizos peruanos llevar armas, salvo que cuenten con un permiso especial de las autoridades, estos se sintieron afrentados, y como se recoge en un testimonio de la época ${ }^{31}$ solo los moriscos en España podían ser tan despreciados:

"todos tiene grande y justo sentimiento, pues la culpa de algunos particulares no habia de redundar en una tan general y pública deshonra, especialmente habiendo entre ellos muchos hijos de hombres principales y conquistadores de aquel reino, que andan tan señalados e infamados como los moriscos en España. Y solo sirve hacerles esta afrenta de que el que intentare alguna traición halle quinientos, sin honra y desesperados, en el reino que por salir de aquella infamia le sigan, como cabe en cualquiera buena consideración"

Los moriscos no gozaban de estima alguna, ni dentro ni fuera de los reinos peninsulares; cuentan incluso con menos crédito y estima que los mestizos, con los que, por otra parte, podría establecerse algún paralelismo. Así, no deja de ser elocuente el testimonio del obispo de Cuzco, Sebastián de Lartaún, de 1580, cuando considera que los segundos son los mejores clérigos con que se puede contar para la evangelización de los indígenas porque conocen el lenguaje y las costumbres, y son gentes devotas y de moralidad intachable, y no como los judíos y moriscos:

"dellos (los mestizos) no se debe presumir lo que de confesos y moriscos porque estos tales tienen ley o secta a lo que dicen rebelada a que están con mucha porfia obedientes los unos a la de Moysen y los otros a la de Mahoma, $y$ los naturales desta tierra ninguna tuvieron a que puedan estar tan afectados (sic) y vendidos como ellos a la suya",32.

Una mediación, pues, necesaria, pero que parte del descrédito y de la desconfianza del cristiano viejo.

31 Memorial de Cristobal Maldonado (ca. 1574) en Archivo General de Indias, Patronato 192, $\mathrm{n}^{\circ}$ 2, $\mathrm{r}^{\circ} 19$, imgs. 6-7, citado por Berta ARES QueIJA, "El papel de mediadores y la construcción de un discurso sobre la identidad de los mestizos peruanos (siglo XVI)", Entre dos mundos. Fronteras culturales y agentes mediadores, Berta Ares y Serge Gruzinski (coords.), CSIC, Sevilla, 1997, p. 48.

32 Carta del obispo Sebastián de Lartaún al rey (Cuzco, 19 de septiembre de 1580), recogida por Berta Ares QueIJA, "El papel de mediadores...”, p. 50. 


\subsection{De las competencias del mediador eficaz. Intérpretes, traductores y mediadores}

Alfonso X en las Partidas ${ }^{33}$ ya señalaba las características que debía reunir un alfaqueque, como hemos mencionado con anterioridad. El rey exigía que fueran hombres de buena $\mathrm{fe}$, sin codicia, que conociesen la lengua del reino que visitaban para evitar incidentes a causa de su ignorancia, que fueran esforzados y sufridos y que tuvieran bienes propios para garantizar el pago de los rescates ${ }^{34}$. Esas competencias y obligaciones se convertirán en normativa jurisdiccional para toda la frontera de Granada a raíz de los Ordenamientos de Alcalá de Henares de 1348 y en las Cortes de Toro de 1371. Las seis cualidades que establece el rey "Sabio" se convertirán en la base fundamental de la actuación de todo alfaqueque en los siglos XV y XVI ${ }^{35}$.

Esas cualidades no se alejan demasiado de las que Corsellis ${ }^{36}$ establece para caracterizar al mediador cultural:

- Confidencialidad: respetar el derecho a la vida privada de los otros

- Imparcialidad: no tomar partido por ninguna de las partes

- Exactitud/ Fidelidad: asegurarse de que el mensaje es fiel al original y apropiado en el nuevo contexto cultural

- Integridad: ser honrado con uno mismo y su capacidad o habilidad a la hora de aceptar un trabajo de Intérprete/traductor ${ }^{37}$.

Estos son también los principios que deben guiar la labor de un buen traductor/mediador en los siglos que estamos estudiando, a juzgar por el testimonio que se recoge en una petición de 1503 a la reina en la que se solicita que autorice al concejo de Granada la provisión de un intérprete para los veinticuatros moriscos:

"Sepades que por parte de los regidores desa dicha çibdad nuevamente convertidos a nuestra santa fee catolica, me fue fecha relaçion diziendo quellos estan puestos [tachado: jus] juntamente con los otros regidores desa dicha çibdad para ver e prover en las cosas del regimiento e governaçion della. E que entran en los cabildos e ayuntamientos. Que a cabsa de no entender la

\footnotetext{
33 II Partida, título XXX, leyes 1, 2 y 3.

34 Juan Torres Fontes, "Los alfaqueques castellanos en la frontera de Granada", Homenaje a don Agustín Millares Carló, Caja Insular de Ahorros de Gran Canaria, Las Palmas de Gran Canaria, 1975, p. 102. Reeditado en Instituciones y sociedad en la frontera murciano-granadina, Real Academia Alfonso X el Sabio, Murcia, 2004, pp. 267-294.

35 Mercedes Abad Merino, "Aquí hay necesidad de persona capaz...”, p. 8.

36 A. Corseluis, "Formación de los proveedores de servicios públicos para trabajar como intérpretes y traductores. Habilidades y competencias interculturales", Traducción e interpretación en los servicios públicos. Contextualización, actualidad y futuro, C. Valero (ed.), Comares, Granada, 2003, p. 71.

37 Citado por Raquel Santana Falcón, "El mediador cultural...", p. 40.
} 
lengua, no saben ni entienden cosa alguna de lo que se habla e prouee en el dicho regimiento. E que por esta cabsa, no dan paresçer ni voto en los cabildos e ayuntamientos. E sy le dan, tanpoco se entiende lo que dizen. E si algo les paresçe que se deue proueer, no tyenen ynterpetre que lo diga. Lo qual es cabsa quellos no pueden vsar de sus ofiçios commo deuen ni dar dellos la cuenta que deuen. E me suplicaron e pidieron por merçed sobrello mandase prouer mandandoles dar vn ynterpetre, persona fiable que supiese la vna lengua e la otra, que estuviese en los dichos cabildos e ayuntamientos e les dixese las cosas que se platycasen e fordenasen en ellos para que ellos diesen su voto e paresçer o que sobre ello proueyse (sic) commo la mi merçed fuese" ${ }^{\prime 3}$.

Como se destaca, el requisito fundamental que se pide a esta figura es que sea persona fiable, porque la integridad es un rasgo fundamental en el desarrollo de las funciones que cabe atribuirle; en este caso se espera no solo que traduzca, sino que explique lo que se dice, puesto que se trata de leyes y normas castellanas diferentes a las del antiguo reino de Granada, y que traslade lo que este grupo de moriscos quiera responder. En lo que se insiste:

"Por quanto mi merçed e voluntad fuere pongays un ynterpetre que la vos paresca, persona fiable, el qual sobre juramento diga e declare a los vnos e a los otros lo que fuere necesario" 39 .

Situación muy parecida es la que se dio entre cristianos nuevos de la ciudad de Guadix en 1504, que se quejaban de trato discriminatorio y abusivo recibido por parte de los recaudadores y arrendadores de las alcabalas de dicha ciudad, quienes, obviando su desconocimiento de la lengua castellana, incurrían en todo tipo de atropellos intolerables:

"Sepades que por parte de los christianos nuevamente convertidos a nuestra santa fe catolica, vesinos e moradores de la dicha çibdad [de Guadix] e su tierra, nos fue hecha relaçion disiendo que los arrendadores e recabdadores e arrendadores menores de las rentas de las alcaualas desa dicha çibdad e su tierra, los çitan e enplaçan muchas veses a ellos e a sus mugeres e fijos, sobre lo tocante a las dichas rentas, e les piden e demandan muchas penas e achaques. E no consyenten ni dan logar a que respondan ni aleguen de su derecho por propio que segund el tenor e forma de las leyes de nuestro quaderno de alcaualas lo han de responder ellos mysmos por sy. E que commo son [tachado: $y n c ̧ i e l]$ ynorantes e no saben fablar la lengua castellana, ni estan

38 Archivo General de Simancas. Registro General del Sello. 1503, febrero, fol. 39.

39 Ibídem. 
ynformados de las leyes del nuestro quaderno de alcaualas, les condenan en muchas de las dichas penas e achaques ynjustamente $e$ se les fasen otros muchos agrauios e synrasones ${ }^{\prime \prime 40}$.

No solamente ignoraban la lengua castellana, sino que además desconocían las leyes, por lo que necesitaban de alguien que actuase como intermediario entre dos universos tan distantes, para lo cual, se pedía autorización para que pudieran servirse de procuradores:

“...mandamos que por tiempo de tres annos primeros syguientes contados desdel dia de la data desta nuestra carta en adelante en los pleitos e cabsas tocantes a los dichos christianos nueuamente convertidos desa dicha çibdad e su tierra que no supiere fablar e entender buenamente la lengua castellana, los admitays que respondan e digan e aleguen de su derecho por procuradores, por quanto son personas que segund las leyes de nuestro quaderno de alcaualas deven ser admytidos por los dichos procuradores por no saber fablar e entender la dicha lengua castellana e por no estar commo no estan ynformados de las cosas en ellas contenidas" ${ }^{\prime 4}$.

Del mismo modo, cuando no observaban esta conducta, los intérpretes eran desacreditados. En el pleito por los límites entre Orce y Vélez Blanco contamos con un ejemplo muy elocuente sobre el poco crédito que merece el emisor y la desconfianza que genera el intérprete de la otra parte. Aparece en el testimonio de Alonso Laubini, de Cúllar, de unos cincuenta y cinco años de edad:

"A la sesta pregunta dixo que sabe quel dicho termino despues que este testigo se acuerda, que podra ser de treynta annos aca poco mas o menos, que el dicho lugar de Orze tenia el dicho termino por herençias desde los dichos mojones. Preguntado commo lo sabe, dixo que porque lo oyo desir a los dichos vallesteros. Dixo Fernando de Cardenas, ynterpetre de Veles, que este testigo que depone en las repreguntas que le hazen, es tan vario que no fasia fee su dicho, e quel ynterpetre de la parte contraria avia dicho al testigo: «Mira lo que dizes que heres vn buey»" [fol. 24r $]^{42}$.

En este caso el intérprete de la parte de Vélez, rompiendo su invisibilidad, le manifiesta abiertamente su desconfianza al juez, tanto porque el testimonio del testigo es cambiante como porque el intérprete de la otra parte se ha dirigido al testigo, indicándole cómo

\footnotetext{
40 Archivo General de Simancas. Registro del Sello. 1504, febrero, fol. 38.

41 Ibídem.

42 Archivo General de Simancas. Consejo Real. Leg. 54. El marcado es nuestro.
} 
ha de contestar; es decir, quebrantando los principios que deben regir la conducta y el hacer del intérprete. Esta intervención pone de manifiesto que sus labores no consistían simplemente en traducir, sino que tenía una responsabilidad sobre todo el proceso.

Efectivamente, en la intermediación intervienen otros aspectos más allá de los puramente lingüísticos. Los intérpretes suelen estar sujetos a los intereses de las partes y no siempre pueden ser objetivos; es más, en muchas ocasiones son claramente parciales. Como pone de manifiesto el ejemplo que citábamos al principio de este trabajo, procedente del pleito de límites entre Oria y Cúllar de 1535, se recoge la conducta poco ejemplar del intérprete Francisco Hernández, quien pretendía comprar el testimonio de un cristiano nuevo para favorecer a su parte:

"La qual dixo a este testigo quel dicho Francisco Hernández rogava e importunava a un cristiano nuevo que iba con él que jurase e dixese su dicho en cierto pleito. E que el dicho cristiano nuevo le respondía que él no sabia nada de aquello que le decía el dicho Francisco Hernández, e qué quería que jurase $" 43$.

No obstante, en algún caso es el intérprete el que se ve descalificado por una conducta poco decorosa, alejada de las cualidades que se le deben reconocer ${ }^{44}$ :

"Al interprete de la parte contraria, esaminando sus testigos, le vido haçer muchas señales e dar del pie y del codo para que dixesen lo que quería. E lo pasó [el recusador] e disimuló" ${ }^{45}$.

\subsection{El clero. Intermediario lingüístico}

El clero desempeñó en el periodo morisco un papel especialmente destacado porque la integración de los nuevos convertidos requirió una intensa labor misional que los condujera a la conversión verdadera, y para conseguir este propósito fueron varias las estrategias desplegadas, con mayor o menor fortuna, en las que su intervención será completamente necesaria. En esta cruzada se vieron involucrados todos los estamentos, por lo que contamos con testimonios de obispos, pero también de párrocos de pequeños pueblos, lo que puede ilustrar la condición mediadora que estamos abordando con veracidad.

\footnotetext{
43 Véase nota 3.

44 Mercedes Abad Merino y Juan Francisco Jiménez AlcÁzar, “Item si sabe...”, p. 34.

45 Pleito entre el marqués de los Vélez y Baza por los límites entre Oria y Cúllar. Archivo Municipal de Baza, leg. 90.
} 
Una de las propuestas fue, precisamente, utilizar el árabe como lengua de evangelización, ya que el conocimiento del castellano por parte de la población rural morisca era muy escaso $^{46}$.

Martín de Ayala, obispo de Guadix, por ejemplo, consideraba que el uso del árabe en la predicación de los moriscos era un factor indispensable, por lo que centró todos sus esfuerzos en conseguir un clero plenamente capacitado, lo que significaba que tuviera una competencia lingüística en árabe reconocida. Este propósito, como señala Garrido García $^{47}$, se podía alcanzar de dos formas: mediante cristianos viejos que conocieran la lengua, lo que era poco frecuente, o consiguiendo que moriscos completamente integrados se consagraran como sacerdotes, aunque esta segunda opción contaba con el obstáculo que suponía la provisión real de Carlos I de 1526, que por el estatuto de limpieza de sangre impedía el nombramiento de beneficiados moriscos o descendientes de morisco en el obispado de Guadix:

“...son reconçiliados, hijos o nietos de quemados por el dicho Santo Ofiçio de la Ynquisición o nuebamente conbertidos en nuestra Santa Fe Cathólica para que a ninguno desta calidad no instituyáis ni coleis en ninguna dignidad, raçión, capellanía ni benefiçio"48.

El obispo Ayala también estableció que los domingos de Adviento y Cuaresma y en otras fiestas se reunieran los moriscos en la iglesia, en ciudades como Baza o Guadix ${ }^{49}$, con el fin de

"tener sermón en aráuigo acerca de la doctrina y euangelio que ocurriere, no auiendo en todas las parrochias hombres doctos y aráuigos que los puedan enseñar, y esto hagan los prelados con intérprete o pongan quien lo haga"s0.

En esas mismas disposiciones, en el título II, se establece la contratación en Cuaresma de confesores que hablen el árabe y la predicación una vez al mes en esta lengua "porque algunos en muchos lugares no saben aljamía y puedan entender lo que rezan".

46 Mercedes Abad Merino, "La ejecución de la política lingüística...".

47 Carlos J. Garrido García, "El uso de la lengua árabe como medio de evangelización-represión de los moriscos del reino de Granada: nuevos datos sobre Bartolomé Dorador, intérprete y traductor de Martín de Ayala, obispo de Guadix”, Miscelánea de Estudios Árabes y Hebraicos, 57 (2008), p. 126.

48 Archivo Histórico Diocesano de Guadix. Caja 83, legajo 15, pieza J. Real provisión de Carlos I. Granada, 3 de noviembre de 1526. Recogido de Carlos J. GarRIDo GarCía, "El uso de la lengua árabe...", p. 126.

49 Carlos J. Garrido García, "El uso de la lengua árabe...", p. 128.

50 Martín de Ayala, Sínodo de la Diócesis de Guadix y Baza, facsímil con estudio introductorio de Carlos AsenJo, colec. Archivum, Universidad de Granada, Granada, 1994. Título I, constitución II, fol. 2v. 
Con fray Jorge de Benavides tenemos un buen ejemplo de esta práctica, pues cuando pide que se le pague lo que se le debe por su trabajo, explica claramente las características y condiciones de su función en las Alpujarras:

"Vuestra merçed sabra que despues que se convertieron estos christianos nuevos del reyno de Granada, el señor alçobispo de Toledo y mis prelados me mandaron estar en las Alpuxarras para que predicasse y confesase e instruyesse a los christianos nuevos, porque hallaron que yo sabia muy bien la lengua arauiga, porque estue aqui captiuo en rehenes del comendador de Sauiote"s1.

Esta cuestión queda recogida con más detalle aún en otra carta:

"Frai Jorge de Benauides, fraile professo de la orden de San Françisco de la Obseruançia, dize que por quanto abra mas de cincuenta annos y algunos mas, que por mandado de su magestad y de los Reyes Catolicos, ha residido y reside en Andarax y en Verja, que son en las Alpuxarras de Granada, entre los moriscos nuevamente conuertidos, predicandoles y dotrinandolos en la lengua arauiga donde ha echo mucho seruicio a Dios y a su magestad. Por lo qual, teniendo su magestad y los Reyes Catolicos, de gloriosa memoria, respeto al bien y probecho de aquellas gentes y el gran seruicio que a Dios se haze con su dotrina, porque perseuerase en tan buena obra, mandaron los Reyes Catolicos y su magestad por çedula y sobreçedula prouer al dicho frai Jorge de Benauides quinze mil maravedies para su sustentaçion, librados y pagados en la renta de los habizes, en cada vn anno. Y agora al presente se le pagan. Por lo qual, viendose ya viejo, que es de hedad de çiento y çinco annos y no querria morir entre los moriscos, suplica a su magestad que, teniendo respeto a los muchos annos que ha seruido que es despues que se tomó la ciudad de Granada, le aga bien y merçed que los dichos quinze mill maravedies que le manda dar, residiendo en la dicha Alpuxarra, se los mande librar residiendo en la çiudad de Granada, porque desde alli puede hazer el mismo seruiçio, visitandolos y dotrinandolos en todo lo que pudiere conforme a su hedad y veges, $y$ en esto se ara a Dios muy gran seruiçio y a él muy grand merçed y limosna"s2.

En las parroquias con mayor número de cristianos nuevos era frecuente, o al menos conveniente, que los párrocos y beneficiados conocieran el árabe, lo que no significa

51 AGS. Cámara de Castilla. Leg. 0345. 26 de septiembre de 1554.

52 AGS. Cámara de Castilla. Leg. 0345. Para este personaje, véase además, M. Carmen Calero Palacios: "Nuevos datos sobre el adoctrinamiento de los moriscos. Actuación de fray Jorge de Benavides en las Alpujarra", en L'Expulsió dels moriscos conseqüencies en el món islámic i el món cristiá, Barcelona, 1994, pp. 300-304. 
que todos tuvieran un conocimiento profundo de la lengua, como ponen de manifiesto los datos procedentes de los nombramientos de nuevos beneficiados en Motril y la Alpujarra. Como se verá en los siguientes ejemplos, la cualidad de hablar arábigo era un mérito más en la oposición que se realizaba para cubrir las vacantes. Estos fueron los opositores seleccionados para cubrir las vacantes en la Iglesia de Santa María de la Encarnación, en Motril:

"El primero Juan Fernández Garauato, el qual es natural desta çiudad, legitimo christiano viejo y tenidos sus padres en reputaçion de hidalgos. Es hombre honesto y recogido, de buenas costumbres. Lee y construye y entiende gramaticalmente bien y canta medianamente, habla latin congruamente (sic) y dio mediana razón de los sacramentos. Y sabe bien algarauia”.

El segundo, Francisco de Luque, natural desta çiudad, legitimo, sus padres son tenidos por christianos viejos. Es honesto de buena vida y fama y costumbres, lee bien y construye medianamente y entiende poco y canta poco habla latin congruamente y dio mediana razon de los sacramentos. Sabe hablar aravigo. Oyo dos años de canones en esta universidad.

El terçero es Anton de Robles, natural de Carauca, legitimo christiano viejo $y$ tenido por hijodalgo. Lee y construye bien y entiende medianamente, dio mediana razón de los sacramentos, no canta bien. Sabe aravigo hasta echar las fiestas y otras cosas concernientes a su offiçio. Fue colegial en el colegio de los clérigos desta çiudad A que reside en ella y su arçobispado mas de doze annos, y a estudiado y cantado misa en ella. A seruido y sirue en este arçobispado XXX curados. Es de buena vida y fama"53.

Otro tanto podemos encontrar en la vacante del lugar de Alhabia, en plena Alpujarra almeriense, perteneciente también a la Iglesia de Santa María de la Encarnación:

"El terçero es Gaspar Lopez, natural desta çiudad, legitimo, sus padres fueron tenidos en posesión de christianos viejos y a muchos años que poblaron esta çiudad. Es hombre honesto de buena fama y costumbres. Lee y construye y entiende literalmente medianamente entiende un poco la sentençia, dio alguna razón de los sacramentos, canta medianamente, sabe echar las fiestas en aravigo y vn poco de pratica y los mandamientos" ${ }^{54}$.

\footnotetext{
53 Archivo General de Simancas. Cámara de Castilla. Leg. 0289. El marcado es nuestro también en los casos siguientes.

54 Ibídem.
} 
O en el puesto de beneficiado de Darrical, también en la misma comarca alpujarreña de Almería aunque lindando con la granadina, donde se da la circunstancia de que uno de los seleccionados es hijo de morisca:

"El bachiller Francisco de Torrijos es natural de Vxijar, del Alpuxarra, cerca de Darrical, donde está vaco. El beneficiado es hijo natural de vn christiano viejo y una morisca que anda en habito de christiana vieja. Es bachiller en Artes, graduado en esta Vniversidad. Es de buena vida y costumbres, lee mas que medianamente, construye y entiende gramaticalmente bien, habla congruamente latin, canta poco aunque se muestra docil para el canto, dio mediana razon de los sacramentos y habla bien en aravigo, y es de buena vida y costumbres" ${ }^{\prime 5}$.

También hallamos a Gaspar López, que es hijo de cristianos viejos, y muestra cierta competencia en árabe, aunque no lo hablase bien:

"Gaspar López es natural desta çibdad, legitimo, sus padres fueron tenidos en possesion de christianos viejos y a muchos años que poblaron esta çibdad. Es hombre de buena fama y costumbres, lee, connstruye y entiende literalmente medianamente y entiende vn poco la sentencia, dio alguna razón de los sacramentos, canta medianamente, sabe echar las fiestas en aravigo y vn poco de platica y los mandamientos y a tenido cargo de animas" $"$.

\section{Entender el mundo. Negociar significados}

La lengua, como sistema lingüístico, constituye una forma de ver el mundo y de organizar la realidad. Cuando hace falta la intervención de un traductor para trasladar el mensaje a otro sistema lingüístico diferente, la lengua fuente no perderá esa propiedad completamente, pero tendrá que compartir algunas de sus particularidades con la lengua meta, lo que adquiere una relevancia especial en la situación comunicativa que nos ocupa, pues dos mundos tan alejados política y culturalmente van a necesitar una adaptación, en ocasiones, bastante compleja.

\footnotetext{
55 Archivo General de Simancas. Cámara de Castilla. Leg. 0293. Para la vida y la trayectoria de este interesante personaje, un auténtico "agente doble", véase Javier CASTILlo FERnÁndez: "El sacerdote morisco Francisco de Torrijos: un testigo de excepción en la Rebelión de Las Alpujarras", Chronica nova: Revista de historia moderna de la Universidad de Granada, 23 (1996), pp. 465-492.

56 Ibídem.
} 
En nuestros documentos contamos con algunos ejemplos que pueden servir para ilustrar de qué manera el intérprete tiene que adaptar la realidad a través de las palabras; necesita encontrar la equivalencia y convencer a las partes de que su interpretación es fiable.

\subsection{De instituciones y conceptos políticos}

Como ya hemos dicho, la conquista de Granada trajo consigo la necesidad de incorporar al sistema político castellano todas las instituciones y costumbres nazaríes, así como el sistema fiscal. Del mismo modo, hubo que delimitar los nuevos territorios según la estructura territorial castellana, lo que resulta crucial a la hora de fijar los límites de los términos jurisdiccionales. Esa es la razón de que los pleitos por límites territoriales nos ofrezcan algunos ejemplos muy ilustrativos de lo que proponemos.

En el pleito entre la ciudad de Vera y las villas de Sorbas y Lubrín por la delimitación de sus términos ${ }^{57}$, todas las pruebas y testimonios esgrimidos tienen como fin último demostrar históricamente la extensión de los límites bajo dominio nazarí, para justificar así que se mantenga su demarcación primitiva tras la conquista castellana. Así, cuanto más antiguo sea el documento, mayor validez tendrá la argumentación de las partes; de ahí que en este pleito se manejen algunos documentos en árabe, que necesitan obligatoriamente de un traductor ${ }^{58}$.

La interpretación que se haga será crucial para la defensa de los argumentos esgrimidos: la traducción de la expresión "teniente del cadí de Vera" puede procurar el éxito a una de las partes. En este caso, la función del romanceador va más allá de encontrar la palabra adecuada; debe encontrar la equivalencia y justificar el significado para unos receptores ajenos al universo conceptual establecido por la lengua árabe y desconocedores de las instituciones nazaríes. Los intérpretes han de actuar como puente entre ambos mundos. Para la ciudad de Vera, "teniente de Cadí de Sorbas", ha de interpretarse de la siguiente forma:

“...Lo otro porque en lo que algunas de las escrituras dizen teniente de cadi de Sorbas, entenderse a que hera teniente el cadi de Bera questa a la sazon en Sorvas, en caso que las dichas escrituras obiesen de hazer alguna fee o credito..." ${ }^{\prime 9}$.

Para la parte de las villas de Sorbas y Lubrín, el significado es diferente:

"Lo otro porque la suplicaçion e ynterpretaçion que la parte contraria quiere dar a las escripturas que presento mi parte donde se haze mençion del

37 Archivo de la Real Chancillería de Granada. 583-2.

58 Mercedes Abad Merino, "La traducción de cartas árabes en un pleito granadino del siglo XVI...".

59 Ibídem, p. 503. 
teniente de cadi de Sorbas es muy violenta y torçida, y contra el verdadero entendimiento y palabras del, porque teniente de cadi de Sorbas quiere dezir a sentido de qualquiera que bien lo entendiere que en Sorbas avia / / cadi y que este para las cosas que alli ocurrian no tan prinçipales ponia teniente. Que si fuera como la parte contraria [entrerrenglones: dize] avia dos teniente de cadi de Vera, quanto mas que todos los cadis venian nonbrados del rey de Granada, como los alcaydes y alfaquyes segund consta por este proçeso, porque pido y suplico a vuestra alteza mande lo en todo segund tengo pedido para ello ynploro vuestro real favor e pido justiçia y costas" $"$.

La delimitación territorial del antiguo reino de Granada no se basaba en amojonamientos oficiales, sino en la tradición y en los límites naturales, por lo que llegar a trasladar su equivalencia en términos castellanos supone todo un ejercicio de adaptación cultural. Es lo que sucede cuando los testigos dan su versión de esta realidad en algunos de los pleitos surgidos para esta delimitación territorial; hacemos alusión al pleito ya referido entre doña María de Luna y don Pedro Fajardo Chacón, primer marqués de los Velez, por los límites entre Orce y Vélez Blanco:

"A la segunda pregunta dixo que todos los pueblos heran hechos vn maçamorro, que los ynterpetres declararon que desia que hera vna $<$ comunidad $>$ [tachado: rebuelta] e conpannya entre todos. [Tachado: Preguntado que] $e$ que en la ora que a vna neçesidad cada vno conosçia su termino. Preguntado cómmo lo sabe, dixo que porque cada villa en tienpo de guerras ponian sus guardas en sus terminos e que asymismo se lo dixo Escovar, pariente suyo que se desya Azeyte. E que por esto lo sabe" [fol. 15r $]^{61}$.

Los intérpretes intervienen para explicar cómo debe entenderse el término "maçamorro", aunque por la vacilación del escribano parece que debió haber cierto debate, ya que primero escribe "revuelta" y después lo tacha y sobreescribe "comunidad". Esta interpretación estaría muy próxima a la respuesta de otro testigo, Ruy Diez Alfaraz, morisco de Cúllar, quien utiliza la imagen de "un bulto":

"A la quinsena pregrunta dixo que la villa de Galera no tyene ter[mino]. Preguntado commo lo sabe e commo esta syn termino. Dixo que Orze e Galera e Castillejar e Huesca todo es vn bulto, e que por esto dise [que] no tyene termino" [fol. 11r].

\footnotetext{
60 Ibídem, p. 504.

61 Archivo General de Simancas. Consejo Real. Leg. 54. Como en el caso anterior, las siguientes referencias pertenecen a esta misma pieza documental. Todos los marcados son nuestros.
} 
Hay conceptos tan asumidos que no necesitan ser glosados; es más, unas veces aparecen mencionados con su nombre árabe y en otras ocasiones con el equivalente aproximado en castellano, como es el caso de "rami", que aparece indistintamente en árabe o con su equivalente castellano, que es "ballestero":

"A la terçera pregunta [tachado: dixo que] de los rastros dixo que vn dia saltearon çiertos christianos en el termino de Oria, e que salio el rami Caguaz con dos mançebos, e con este testigo que heran tres. E que tomaron el rastro de los dichos christianos e lo traxeron hasta el puerto del Cherivel. E que estando en el dicho puerto [54v] hallaron alli vn onbre grueso que hera vesino de Orze que se desia el rami Bulfat, e que el dicho rami les dixo: "¿Qué es esto?». Y que [tachado: este testigo e los] el dicho vallestero que venia con este testigo e con los otros, le dixo: "Ves aqui este rastro que traemos de los almogavares»»" [fols. 54r-v].

\subsection{De impuestos y recaudaciones}

La misma situación que hemos descrito en al apartado anterior para la equivalencia entre las instituciones es la que va a reproducirse en el caso de los impuestos ${ }^{62}$, aunque en esta ocasión particular la repercusión económica que puede tener una interpretación u otra es la que hace imprescindible que los intérpretes conozcan plenamente las costumbres de moriscos y castellanos y no solamente la lengua. Aunque en este ámbito específico las cuestiones lingüísticas se ven sobrepasadas por los intereses económicos.

La complejidad de la estructura fiscal del reino de Granada, como muestra Galán Sánchez ${ }^{63}$, tuvo un papel considerable en la conservación de la lengua árabe después de la conversión, puesto que a la Corona le interesaba conservar la eficiente y compleja política recaudatoria preestablecida a través de una sólida estructura construida en árabe, hasta el punto de que los libros de cuentas aparecerán solo en árabe o en árabe y castellano. Para garantizar el éxito de la gestión tributaria nazarí, aunque oficialmente hubieran desaparecido los tipos tributarios asociados al pasado islámico ${ }^{64}$, debía mantenerse, "adaptarse" a los existentes en la hacienda pública castellana y para ello era imprescindible la presencia del pechero que hablara árabe. Podemos hablar de contabilidades bilingües.

Esto explicaría muchas cosas, como la conservación del nombre árabe para cierto tipo de impuestos y el afán por esclarecer con precisión las particularidades de cada uno de los tributos. Así, en ocasiones esta tarea se convierte casi en un acertijo que debe resolver el agente lingüístico. Es lo que sucede en la encomienda hospitalaria de Archena, en la Vega Media del río Segura, en el reino de Murcia, aljama mudéjar desde el tratado de

\footnotetext{
62 Mercedes Abad Merino, "El intérprete morisco...".

63 Ángel Galán SÁnchez, "Identidad e intermediarios culturales. La lengua árabe y el fisco castellano tras la conquista del reino", Edad Media. Revista de Historia, 17 (2016), pp. 109-132.

64 Ibídem, p. 119.
} 
Alcaraz en 1243 e incorporada, como el resto de la población musulmana murciana, a la condición morisca tras la conversión general de principios del XVI:

\begin{abstract}
“...espeçialmente en quanto el dicho de Françisco del Castillo e Gonzalo Morzillo, quisieron decir que almagran en aravigo quiere deçir çenso, porque lo contrario es la verdad e los testigos por su parte presentados de los convertidos que saben el algarabia e entienden la dicha lengua e naçieron en ella como lo son Lope Carrillo e Pedro Gallego e Juan Manuel e Françisco de Bovadilla, vezinos de Ricote, no disen ni declaran que almagran quiere decir çenso en aravigo, antes bien e con diligençia examinados sus dichos fasen en favor del dicho conçejo my parte e fundan su yntinçion y a la dicha mi provança menos embarga lo alegado e aprovado por la parte contraria e quanto dixo, ..."65
\end{abstract}

A cada una de las partes le conviene una interpretación diferente porque de ella dependerá el derecho a quedarse con un porcentaje de ese dinero, y la respuesta a si los cristianos nuevos deben seguir tributando como moros o ya no, al estar bautizados.

Otras veces, a pesar de no traducir el término, se busca su equivalencia mediante una explicación del contenido, con más o menos matices. Es lo que sucede con el derecho del talbix ${ }^{66}$, vocablo que se convierte en una de las preguntas específicas en el pleito de límites entre Orce y Vélez Blanco ya aludido, pues importa que quede muy claro en qué consistía el pago, quién lo debía pagar y quién o quienes lo cobraban:

"Yten por el derecho del tahbix (sic) que pagavan los m[o]ros que no tenian comunydad que entrauan a ervajar [con] sus ganados en los terminos de otros, el qual derecho [roto: devian] de pagar al alcayde del logar cuyo hera el termino donde entrauan a paçer" [fol. 1v $]^{67}$.

Así se recoge también en el testimonio de Diego Alhandache, cristiano nuevo de Cúllar, en el que cabe deducir la intervención de los intérpretes al establecer la equivalencia con otros derechos semejantes, pues el testigo de setenta años no estaría familiarizado fácilmente, suponemos, con los derechos castellanos:

"A la quinta pregunta dixo que lo que desta pregunta sabe es que las personas [tachado: que] e conçejos que no tenyan comunydad con otros qonçejos

\footnotetext{
65 Archivo General de Simancas. Consejo Real. Leg. 40, fol. 331. El marcado es nuestro.

66 Sobre este impuesto, véase Ángel GaLÁn SÁnchez, "Acerca del régimen tributario nazarí: el impuesto del talbix”, Actas del II Coloquio de Historia Medieval Andaluza. Hacienda y comercio, Diputación Provincial de Sevilla, Sevilla, 1982, pp. 379-392.

67 Archivo General de Simancas. Consejo Real. Leg. 54. Como en ocasiones anterior, las referencias especificadas a continuación, pertenecen a este mismo documento, y el marcado es nuestro.
} 
donde yvan a ervajar con sus ganados pagauan el dicho derecho del tahbix al alcaide del lugar en cuyo termino ervajavan ques commo el derecho de borra o asadura o otro semejante que suelen tener los alcaides" [fol. 7r].

Al igual que aparece en el testimonio de Marcoçelin, labrador de Cúllar, de setenta años, donde explícitamente se hace referencia al equivalente castellano, a pesar de que el testigo no hablaba la lengua, por lo que, una vez más, hay que presuponer la intermediación de los intérpretes, conocedores no solo de la lengua, sino también des sistema político castellano:

"Fue preguntado por el derecho del [tah]bix que pagavan los moros. Dixo que oyo desir que sy se avenyan [con el] alcaide los duennos de ganados y pagauan vna noche de leche y [borrado] cosa alguna segund se ygualauan, ques dicho commo en castellano dizen borra e asadura. Fue preguntado que porque pagauan el dicho [borrado], dixo que porque paçian en los terminos a donde lo pagauan" [borrado] [fol. 8r]

La necesidad de una información clara y explícita justifica la reiteración e las preguntas:

Preguntado por el d [erecho] del talbix que se pagaua a los alcaides, dixo que sabe que los ganados que venian de Vera o de otras partes a ervajar a los lugares $d[$ borrado] no tenian fermandad, que pagauan el derecho que dizen el tabix (sic). Preg[untado] que qué derecho hera el talbix, dixo que el que el alcaide queria, que hera [borrado] de çient cabeças le tomaua vna o vna noche de leche de todo el gan [ado] segund lo queria haser en ellos" [fol. 9v].

"Preguntado çerca del derecho de talbix, dixo saber que quando algund forastero venia con ganado, el alcaide les tomava el ganado que se le antojaua e les tomava carne. Preguntado cómmo lo sabe, dixo que porque asy hera vso e costunbre entre los moros. Preguntado que qué derecho hera el talbix, dixo que de çiento vno e que esto se vsaua e guardaua entre moros" [fol. 16r].

\subsection{La toponimia}

La importancia de la toponimia en estos pleitos es fundamental, ya que, como hemos dicho, la delimitación de los territorios tradicionales nazaríes no se fundamentaba en la misma concepción que la de los territorios castellanos, pues los límites no se establecían mediante mojones oficiales, sino que los usos y costumbres jurisdiccionales de los cadiazgos los establecían hasta un río, una sierra, un tronco de árbol, etc. La inexistencia de un sistema de alfoces tan estructurado como el castellano, fue lo que desembocó 
en el proceso ya aludido de definición concejil en los nuevos municipios granadinos, ya incorporados a Castilla. Acerca de estas referencias en el terreno, podemos referir algunos casos recogidos en el pleito aludido entre doña María de Luna y el marqués de los Vélez; este es un buen ejemplo:

"Fue preguntado sy las dichas çibdades, villas e lugares tenian mojones e sennales por donde coonoçia cada vna sus terminos. Dixo que nunca vio mojones, pero que vio cabeças de syerra e sennales e ranblas por donde le desian que se partyan los términos" [fol. 36r].

De ahí que sea esencial establecer la equivalencia entre los topónimos en tiempos de moros y en tiempos de cristianos, debido básicamente a las consecuencias que puede implicar una confusión en alguno de los lugares de delimitación. No es de extrañar, pues, que se le exija al intérprete, una vez más, una competencia pragmática más allá de la lingüística:

"Yten sy saben e etc que la dicha villa de Orçe, asy en tienpo de moros commo despues aca que es de christianos ha partydo e parte sus terminos con la dicha villa de Velez el Blanco por los limites e mojones syguientes: el primero mojon en lo alto de la cumbre de la syerra, en el puerto del Chirivel, que en aravigo se dize Fegetrabit, e de alli viene por su derechera a otro mojon que dizen la loma del Alfaguara, e de alli por su derechera a la huente del Agua [2r] Blanca que en aravigo dizen Almi Alabiad, donde veni[an] a bever los ganados de Orçe e Velez, como apartymiento de [ter]minos. E de alli a otro mojon que dizen el puerto del Saladar, que en aravigo dizen Fajal Molaylaha, don[de] acaban de partyr terminos Orçe e Velez e comyençan a partyr terminos Velez con Huesca" [fol. 2].

"A la quinta pregunta dixo que su padre deste testigo le dixo que los terminos de Orze e Veles el Blanco se partyan por el puerto del Cherivel, que en aravigo dizen Fextrebit" [fol. 12r].

"A la tresena pregunta dixo que sabe que se ponian las guardas en Fexetrabit, que se dize agora el puerto del Cherivel" [fol. 14v].

"Preguntado que por que partes se partyan los dichos terminos en tienpo de moros, dixo que desde el puerto del Cherivel que en aravigo dizen Fexetravit, e de ay al lomo del Alfaguara, e de ay al Agua Blanca, que en aravigo se dize Almealabiat, e de alli al puerto de la Salinilla, que se dise Fexealmolaylaha" [fol. 45r]. 
Aunque a veces no se traducen:

"A las diez e ocho preguntas dixo que sy el termino se partyese [tachado: al termino] por el algibe Quebrado e Fex Alcaçar e Afoma Çahara, que los de Orze quedarian çiegos e no avria para las cabras [tachado: quedarian çiegos]" [fol. 13r].

O se nombran en castellano, cuando seguramente el testigo lo dijo en árabe

"Fue preguntado que en que partes e lugares estan los dichos hedifiçios e que hedifiçios son. Dixo que hasia donde dizen Fomaçahara vna milla o dos millas de los dichos mojones estan sennales de corales e colmenares. Es asymismo, en otra parte a donde dizen la Cabeçada de Canapla a la via del Agua Blanca estan alli las sennales de commo estavan alli corrales de barda" [fol. 50r].

Estas referencias son habituales y muy comunes en los pleitos existentes a lo largo y ancho de la línea fronteriza y en el seno del reino de Granada en las primeras décadas del XVI, aunque se irán diluyendo con el paso del tiempo, que también llevara consigo la desaparición natural del testigo morisco monolingüe en árabe y la sustitución del topónimo por el utilizado por el repoblador castellano.

\section{Conclusiones}

La comunicación entre cristianos y musulmanes durante el periodo en el que se mantuvo el sultanato nazarí de Granada, no fue fácil, y no solamente por las evidentes diferencias lingüísticas, sino también por las diferencias religiosas, políticas y culturales en su sentido más amplio. Después, cuando el reino granadino se incorporó a la Corona de Castilla, las dificultades en la interrelación de cristianos viejos y moriscos seguirán siendo las mismas que ya se dieron décadas y siglos atrás, o incluso se acrecentaron, puesto que el hecho de que los nuevamente convertidos no hablasen castellano ni mostraran voluntad de aprenderlo se interpretará como una señal de deslealtad y traición.

Así pues, este panorama formado por dos comunidades lingüísticas diferentes, mayoritariamente monolingües en su propia variedad, explica que los intérpretes se convirtieran en una presencia necesaria y constante en muchas de las situaciones comunicativas cotidianas, ordinarias y oficiales, tanto por sus saberes lingüísticos, como por su conocimiento de ambas culturas. Ante esta evidencia, nos inclinamos a pensar que el intérprete en podía ser considerado como un mediador cultural desde una perspectiva diacrónica, si bien no cabría buscar como finalidad de su intervención la integración de 
culturas, pues sería un anacronismo cuando hablamos de "sociedades paralelas" para describir el modelo social de esos años. Intérpretes y traductores, pues, se convierten en verdaderos intermediarios lingüisticos.

La realidad documental debería permitirnos contrastar estas ideas de partida, aunque en este campo de estudio una de las principales dificultades reside, precisamente, en encontrar esa documentación histórica. En este caso, los valiosos textos con los que contamos hasta el momento y de los que nos hemos servido en la realización del trabajo así nos lo confirman.

Tras el análisis de distintos documentos históricos, principalmente pleitos de límites, hemos podido comprobar que hablar simplemente de traductores para referirse a estas figuras imprescindibles - patentes unas veces, ocultas en otras ocasiones- no refleja plenamente la complejidad de las funciones que llegan a desempeñar.

En su quehacer se ven forzados en ocasiones a manejar ideas y no solo palabras para que la comunicación sea exitosa, por lo que cobran una visibilidad y un protagonismo mayores de los que un traductor suele tener, lo que no solo no interfiere con su función sino que llega a formar parte de ella, pues muchas veces es inevitable que intervengan de una manera explícita, lo que nos ha permitido asumir diversos modelos de intermediación lingüística, igualmente válidos: el intérprete imparcial, que tan solo repite lo que oye y el intérprete que toma partido, aconseja e incluso da su opinión. Pudieron ejercer de intérpretes en tiempo de conflicto, y así, explicar situaciones a las partes en un juicio, dar consejo, o manifestar opiniones sobre un discurso o un testigo.

Pero el intérprete, en este marco histórico en que nos movemos, tiene que combinar sus conocimientos lingüísticos con sus saberes culturales, para poder establecer ese puente comunicativo temporal y sociocultural, desde tiempo de moros a tiempo de cristianos, entre moriscos y cristianos viejos. Así, por ejemplo, conocían el territorio y eran capaces de identificar los parajes para establecer la equivalencia entre los nombres dados antes de la conquista castellana y los utilizados por los cristianos. Del mismo modo, esa distancia cultural a la que estamos apelando, como sucede en el caso de los sistemas fiscales nazarí y el castellano, propicia que para establecer la equivalencia entre términos y conceptos en una y otra lengua sea necesaria toda una labor de negociación entre las partes.

No solo conocían los códigos culturales de ambos mundos, sino que en el caso de los intérpretes moriscos esas competencias se veían implementadas por el sentimiento de solidaridad que se establecía con sus interlocutores cuando también eran conversos, lo que podría explicar que a pesar de la desconfianza generalizada que el cristiano viejo sentía hacia el morisco, este fuera el intérprete más codiciado, aunque el clero también desempeñó una labor muy destacada de intermediación, al servirse del árabe durante un tiempo como lengua de evangelización y al ejercer como traductores fehacientes en las parroquias de cristianos nuevos en las que desempeñaban su misión pastoral.

Los ejemplos y las situaciones que hemos podido analizar nos permiten considerarlos, con toda la precaución que cabe aplicar a una situación diacrónica, como intermedia- 
rios lingüísticos o mediadores, porque en muchos casos sobrepasaron las funciones de un intérprete y actuaron como puente entre los dos mundos, adaptando las diferencias lingüísticas que surgieron como resultado de las diferencias culturales; su intervención aseguró el éxito comunicativo y garantizó la confianza de los interlocutores, que se veían así aliviados del peso que suponía pertenecer a mundos diferentes, a veces enfrentados.

Fecha de recepción: 18 de abril de 2017

Fecha de aceptación: 17 de julio de 2017 
